\title{
Effects of emotional healing on organisational learning and radical innovation: a leadership-based approach
}

\begin{abstract}
Purpose: The objective of this study was to provide empirical evidence of the relationship between emotional healing, analysed as a leader behaviour, and radical innovation.

Design/methodology/approach: To this end, structural equations were used, with organisational learning capability as an explanatory variable. The study was conducted in a population of 402 Spanish companies. A sample frame of 292 questionnaires was obtained from 146 different organisations. The fieldwork took place in two stages, in 2010 and again in 2015.
\end{abstract}

Findings: Results confirm the hypotheses proposed in the model. Emotional healing promotes organisational learning capability and, in turn, radical innovation.

Originality: To our knowledge, there are no previous studies which studied the relationship between emotional healing and its effect on radical innovation. Therefore, providing empirical evidence of such a relationship is the main contribution of this paper.

Practical implications: Our results provide some guidelines for companies that are trying to develop radical innovations by improving the workplace conditions.

Keywords: emotional healing; leadership; radical innovation; organisational learning 


\section{Introduction}

There is a general consensus that innovation plays an essential role in promoting organisational performance and the success of companies. In view of the importance of these potential outcomes, numerous authors have called for further analysis to determine what mechanisms facilitate the development of innovation. Besides, research into the variables that facilitate innovation should differentiate between innovation typologies because their promoters and consequences may be different. One of the most significant classifications is the distinction between radical and incremental innovation (Marvel and Lumpkin, 2007).

The present research focuses on radical innovation, and aims to further knowledge about the variables that facilitate this type of innovation. This is not an arbitrary choice. Radical innovations are revolutionary or discontinuous changes that, according to Gatignon et al. (2002, p.1107) "advance the price/performance frontier by much more than the existing rate of progress", and have the potential to transform existing markets, create new markets, and stimulate economic growth (Marvel and Lumpkin, 2007).

The objective of this study is to analyse how, by healing negative emotions such as suffering or trauma, it is possible to encourage an organisational context favourable to radical innovation. Findings in previous studies suggest that emotions are important to develop innovations. However, from a leadership perspective, there are still some gaps that may be of interest to practitioners and scholars. Specifically, little is known about how emotional healing by leaders influences innovation. In the literature, most of the information about this leadership behaviour appears in theoretical reviews or scale development. To the best of our knowledge, there are no empirical studies that analyse its effects. 
Leadership is a key predictor of creativity and innovation (Hughes et al., 2018) and plays a fundamental role in addressing trauma within organisations (Hilton, 1997). However, most previous studies have focused on leadership styles rather than leadership behaviours. In the same vein, given that leadership styles are broad and include different variables, Yukl (2012) called for more emphasis on concrete leadership behaviours when studying the effects of leaders in an organisational context. This approach would clarify the main characteristics of leaders that can trigger innovation. On the basis of these arguments, this study focused on a specific leader behaviour: emotional healing.

On the other hand, the study of leadership must take into account the organisational context (Porter and McLaughlin, 2006), so additional variables must be studied when analysing the effects of leadership or leader behaviours on different outcomes. Accordingly, many studies explain the consequences of leadership on innovation through mediating variables, being organizational learning capability one of them (Domínguez-Escrig et al., 2016). Vargas (2015) argued that along with an appropriate leadership style, organisational learning is a determining strategy to achieve innovation.

Summing up, the present research empirically analyses the effect of emotional healing as a leader behaviour on radical innovation using organisational learning capability as an explanatory variable. From a population of 402 Spanish companies, we obtained a sample frame of 292 questionnaires from 146 different organisations. The fieldwork was carried out in two stages, the first in 2010 and the second in 2015. 
Insert Figure 1

\section{Theoretical background}

\subsection{Emotions and leaders' emotional healing}

The concept of emotion has evolved over time (Ashkanasy and Dorris, 2017). Frijda (1986) stated that emotion is the experience of a form of biological response to environmental stimulus, resulting in physical and psychological changes and subsequent readiness for action. Consistent with this definition, Ashkanasy (2003: 14) defined emotion as "a set of endogenous and exogenous inputs to particular neural systems, leading to internal and external manifestations". While internal manifestations include subjective feelings experienced by the individual which are interpreted cognitively, external manifestations are related to physiological factors such as respiration, facial expression and posture.

Basch and Fisher (2000) studied emotions in organisational settings and reported that employees exhibit both positive and negative emotions. Among the positive ones, the most commonly reported in the workplace are pleasure, happiness, pride, enthusiasm, relief, optimism, affection and power. Regarding negative workplace emotions, they found that frustration, worry, disappointment, annoyance, anger, unhappiness, embarrassment, sadness, disgust, hurt, fear and bitterness were the most frequent.

From the perspective of organisational psychology and organisational behaviour, emotions are related to behaviour in organizational settings in many ways. For example, an unhappy employee tends to be 
disconnected from their work (Frost, 2003). On the contrary, Ashkansy and Ashton-James (2007) concluded that positive emotion is a necessary precondition of positive organisational behaviour.

Healing is a process of immediate repair that involves movement from a wounded state to a condition of strength (Powley and Piderit, 2008). It refers to the process of becoming healthy after suffering illness or harm (Powley and Cameron, 2006). Powley and Piderit (2008) see healing as an active process that requires social interaction. For instance, a healer is someone to whom a sufferer tells things, a person who listens to, learns and understands, with the aim of counselling, comforting and intervening (Jackson, 1992). Indeed, some research considered that healing cannot be accomplished by an individual alone and requires social intervention (Ayalon, 1998; Powley and Cameron, 2006). Healing includes supporting, caring for, helping and strengthening one another (Powley and Piderit, 2008), and comprises empathy, mirroring, emotional contagion, self-regulation, and mentalizing (Kohrt et al., 2020). Jit et al. (2017) related the orientation of leaders for emotional healing as strongly related to his/her characteristics of listening, empathy and compassion. On the other hand, healing shares characteristics with other concepts such as recovery, coping, resilience or hardiness, with which it is sometimes confused. However, healing has unique features that go beyond these concepts (Powley, 2013; Powley and Piderit, 2008).

Emotional healing usually appears in the academic literature as a behaviour related to servant leaders, as these leaders enhance the emotional health of their followers by promoting a positive climate in the workplace (Jit et al., 2017). Barbuto and Wheeler (2006, p.318) defined emotional healing as "a leader's commitment to and skill in fostering spiritual recovery from hardship or trauma. Leaders using emotional healing are highly empathetic and great listeners, making them adept at facilitating the healing process". In turn, Liden et al. (2008, p.162) considered emotional healing as "the act of showing sensitivity to others' personal concerns". 
According to Barbuto and Wheeler (2006), this leadership behaviour is characteristic of leaders who help followers with their emotional issues, personal traumas and hard feelings. Spears (2002) pointed out that healing helps in the recovery of people's "broken spirits" and those who suffer from emotional harm. These leaders promote an environment in which employees feel free to share personal and professional problems (Barbuto and Wheeler, 2006). In the same vein, Beck (2014) stated that these leaders create a context in which followers feel comfortable talking about their personal and professional issues, so employees have the confidence they need to share their traumas.

Liden et al. (2014) stated that emotional healing refers to leaders' capability to be sensitive to the personal setbacks of followers. These leaders also encourage and offer support to those who need it (Powley, 2013). By providing emotional support, leaders become a role model that followers try to imitate (Liden et al., 2014). In addition, by healing followers' emotions, these leaders empower them and help them to grow (Jit et al., 2017).

Beck (2014, p.301) considered emotional healing as the opportunity to see the world through the eyes of others and identified this as a characteristic of leaders who show empathy and have highly developed listening skills. Apart from understanding others, emotional healing entails a willingness to help others, specifically by providing emotional support and assisting people who need personal healing (Liden et al., 2014). When leaders are concerned about followers and want to lessen their suffering, they may develop an empathetic and compassionate behaviour characterised by patient listening, comforting, calming, guiding, counselling, and a willingness to provide support (Jit et al., 2017). 
Other related concepts in the literature share similar characteristics with emotional healing, such as emotional intelligence, emotional capability or compassion at work. These concepts have been studied to explain, from diverse approaches, how emotions affect different outcomes in the organisational context. However, these concepts cannot be equated with emotional healing. Emotional healing goes beyond these concepts by taking care of followers' emotions and playing a proactive role by listening, supporting and providing guidance to those who suffer and have traumatic experiences at work. 


\subsection{Emotional healing and organisational learning capability}

Organisational learning capability is defined as "the organisational and managerial characteristics or factors that facilitate the organisational learning process or allow an organisation to learn" (Chiva et al., 2007). These authors identified five facilitating factors of organisational learning: experimentation, risk acceptance, interaction with the environment, dialogue, and participation in decision making.

Emotions play an important role in the learning process within organisations. Ikävalko et al. (2020) argued that there are two main theoretical approaches to study emotions within the workplace, namely psychological and sociological. While psychological theories see emotions as an intrapsychic phenomenon and relate them to individual experience, sociological perspectives consider emotions dependent on rules that are culturally constituted and socially shared.

The relationship between emotions and learning has not always been clear. Shipton and Sillince (2012) suggested that the effect of emotions on learning has been underestimated, as the organisational learning literature has traditionally focused on information processing. The connections between emotions and learning have been neglected because emotion has been considered as a barrier, an unthinking and irrational phenomenon, while learning is regarded as a more rational or reflexive process (Simpson and Marshall, 2010).

Nonetheless, in recent decades a great deal of research has highlighted the importance of managing emotions to encourage learning. Antonacopoulou and Gabriel (2001) argued that emotions and learning are interconnected because learning is an emotional process that can be influenced by different types of 
emotion. These authors concluded that on the one hand, emotions are the result of learning but on the other, they may facilitate or hinder learning.

On the other hand, Välikangas et al. (2009) warned of the danger of certain negative emotions that arise when projects fail. These authors highlighted the common belief that people learn more from failure than from success. However, they cautioned that this idea is not always true in the organisational context. When projects fail, employees may experience trauma that leads to disillusionment, cynicism or lack of motivation, thereby inhibiting learning. Mechanisms must therefore be put in place to overcome trauma and facilitate learning. In this context, emotional healing may play an important role by creating a positive workplace climate (Jit et al., 2017).

All these arguments lead to the first hypothesis of the study:

H1: Emotional healing has a positive effect on organisational learning capability.

\subsection{Organisational learning capability and radical innovation}

Organisational learning capability is one of the mechanisms that promote innovation and various studies have provided evidence of its positive role in facilitating the development of innovative outcomes (e.g. Akgün et al., 2007). Furthermore, focusing on innovation typologies, organisational learning appears to have a positive link with radical innovations. In this vein, Huy (1999) suggested that learning is necessary to facilitate radical change due to the risky and unpredictable nature of radicalness. 
On the other hand, the dimensions that make up the organisational learning capability construct seem to be related to innovation in general, and more particularly to radical innovation. Regarding interaction with the environment, acquiring new knowledge from external sources updates current knowledge, which leads to the development of radical innovations (Sheng and Chien, 2016). Besides, García-Granero et al. (2015) found that managers who favour risk taking facilitate an organisational climate in which employees try new ideas, experiment and are more creative. In other words, organisations that have a higher propensity for risk are more capable of developing radical innovations (Slater et al., 2014)

In addition, Slater et al. (2014) highlighted participative decision making as one the mechanisms that promote radical innovation in organisations, since employees share new ideas and creative solutions. These authors also concluded that organisations which foster communication and interaction between team members are likely to develop this type of innovation.

According to Koberg et al. (2003), experimentation is one of the facilitating factors of radical innovation. Experimentation enables organisations to recognise new opportunities, face competition or react to unexpected events. Experimentation entails testing and probing new ideas, moving into unknown territory, learning from failure and striving to achieve success.

Therefore, the second hypothesis of the study is:

H2: Organisational learning capability has a positive effect on radical innovation. 


\subsection{The mediating role of organisational learning capability}

Previous research has found or suggested that concern for employees' or followers' emotions plays an important role in developing organisational contexts that can lead to creativity, innovation or change. Creating new things often involves uncertainty and anxiety. Consequently, fostering positive emotions in employees promotes a healthy workplace that may encourage, among other outcomes, innovation and creativity, as they prompt individuals to think in a new and unconventional way (Gupta, 2015).

According to Powley (2013, p.58) "a key to leadership in healing is the awareness of others and acting on internal values that support the development of individuals and positive organizational dynamics". Instead of becoming critical, blaming others or developing negative behaviours, these leaders respond to difficulties with care, compassion, mutual support, etc. By facilitating such a positive environment, these leaders can promote communication and the trust needed to take risks and experiment, which in turn may lead to the development of radical innovations.

When leaders provide emotional healing and are compassionate to their followers, they create a particular context where experimentation, error acceptance, dialogue or participation are promoted (Worline and Dutton, 2017). These characteristics facilitate organisational learning (Chiva et al., 2007), which in turn maximises radical innovations (Dominguez-Escrig et al., 2016). A similar idea was proposed by Shipton and Sillince (2012) who suggested that emotions, learning and change are inseparably linked.

Managing and healing employees' emotions may help to promote an organisational context favourable to risk taking, experimentation and communication (Akgün et al., 2009), which can lead to the 
development of radical innovations. Leaders who support the healing process facilitate connections between organisational members and external stakeholders, strengthen social relationships and create spaces in which organisational members share challenges and innovative ideas (Powley, 2013) that may lead to the development of radical innovations.

Consequently, the third hypothesis of the study is:

H3: The positive relationship between emotional healing and radical innovation is mediated by organisational learning capability.

\section{Method}

\subsection{Data}

This study was based on a sample frame of Spanish companies considered to have excellent human resources management. The sample frame was composed of 402 companies selected from databases and lists such as 'Great Place to Work', the CRF Institute's 'Top Companies to Work For' and 'Top Employers', and the Merco Personas list of best companies to work for, from the journal Actualidad Económica. A total of 146 companies responded to our questionnaire, representing a response rate of $36.3 \%$. 
The questionnaire was addressed to human resources and innovation managers who had at least two years' experience in their company. Each manager answered one of two different questionnaires, depending on their position. The human resources managers gave their opinion about emotional healing as a leader behaviour and organisational learning capability, while the innovation managers answered the questionnaire about radical innovation. Human resources managers are a reliable source to evaluate leadership styles and learning within organisations (e.g. Domínguez-Escrig et al., 2016). On the other hand, 'innovation managers' is a broad term in which we included product managers, R\&D managers and technical managers. In each company we requested contact with the people in charge of innovation activities. These professional profiles have been used in previous research to study radical innovation (e.g. Domínguez-Escrig et al., 2019). The anonymity of the participants was guaranteed to encourage honest responses and facilitate the reliability of the results and conclusions.

The human resources managers' questionnaire consisted of 18 items measured on a five-point Likert scale, while innovation managers responded to six items measured on a seven-point Likert scale. These items were affirmative statements (Table 1), so that the respondents had to say whether they agreed or disagreed with the idea expressed in each one. The survey was carried out through telephone interviews, a technique that has been shown to facilitate contact with managers.

Several recommendations were followed to avoid common method bias, such as using different endpoint scales or obtaining the information from different respondents and in different moments (e.g. Chang et al., 2010). The fieldwork was carried out in 2010 and again in 2015. In 2010, we obtained responses about emotional healing leader behaviour and organisational learning capability. Five years later, we gathered information about radical innovation. Despite this five-year gap to test the effects of 
emotional healing and organisational learning capability in the development of radical innovation, we asked respondents to focus on their companies' innovations over the past two years (Domínguez-Escrig et al., 2019).

Finally, given that the study was conducted in Spain, all the items were in Spanish. To guarantee the accuracy of the translation, a double back translation procedure was followed.

Insert Table I

\subsection{Measures}

After reviewing the literature, we selected several measurement scales that had already been used and validated in previous studies. The reliability of the scales was assessed using Cronbach's alpha.

Emotional healing as a leader behaviour was measured using the scale proposed by Barbuto and Wheeler (2006). This construct had a Cronbach's alpha of 0.87. Organisational learning capability was measured following the scale validated by Chiva et al. (2007). This scale is made up of five dimensions with 14 items altogether. All the dimensions are reliable, with Cronbach's alpha values above the recommended minimum of 0.7 . The lowest Cronbach's alpha was 0.79 . Finally, radical innovation measurement was grounded on the works by Marvel and Lumpkin (2007) and Gatignon et al. (2002). 
Respondents were asked to think only about the most important product or service innovations their companies had developed in the last two years. This construct obtained a Cronbach's alpha of 0.88 .

\subsection{Control variables}

Firm sector, size and market share were used as control variables as they may influence the development of innovations.

Respondents selected one of the two proposed firm sector categories in the questionnaire, yielding the following distribution: manufacturing companies (29.5\%) and service sector companies (70.5\%)

With respect to their size, the companies were classified as follows: fewer than 50 employees (13.0\%), between 50 and 100 employees (22.6\%), between 101 and 250 employees (26.0\%), between 251 and 500 employees (26.0\%), between 501 and 1,000 employees (8.9\%), and firms with more than 1,000 employees $(3.5 \%)$.

Finally, to evaluate market share, respondents were asked to classify their companies in comparison to their largest competitor, which yielded the following distribution: $5.5 \%$ of the companies have a smaller market share, $51.4 \%$ have a similar market share, and $43.1 \%$ have a larger market share than their largest competitor. 


\subsection{Analyses}

Structural equations and AMOS-23 software were used to test the hypotheses proposed in the conceptual model (Figure 1) by means of the maximum likelihood estimation method. In addition, bootstrapping was used to test the significance of the mediated effect (MacKinnon et al., 2012).

\section{Results}

\subsection{Descriptive statistics and psychometric properties of the measurement scales}

Table II presents the means of the items in each construct, correlations between the constructs, and standard deviations. The psychometric properties of the measurement scales were also evaluated to determine the construct validity (Anderson and Gerbing, 1988). Their dimensionality and reliability were analysed, along with their convergent, discriminant and content validity (Tippins and Sohi, 2003).

Regarding the structure of the constructs, in addition to confirmatory factor analyses, we also followed a common approach in the literature, namely assessing a full measurement model that includes all the variables (Anderson and Gerbing, 1988). Testing a full measurement model establishes the structure of the variables in the context of other variables measured in the study and ensures that the measures used are different from one another. The overall fit of this general model was: Chi square (d.f.) = $311.72(244)$; $\mathrm{p}=0.00 ; \mathrm{CFI}=0.96 ; \mathrm{RMSEA}=0.04$. The Chi square statistic was non-significant and all the standardised estimates were significant and in the expected direction. The constructs were therefore different from one another. 
In addition, reliability analyses were satisfactory (Table III). Composite reliability and Cronbach's alpha exceeded the minimum recommended value of 0.7 (Nunnally, 1978). The average variance extracted was also higher than the minimum accepted value of 0.5 (Nunnally, 1978).

Using previously validated measurement scales ensured content validity. As described above in the Measures section, radical innovation was measured with variables from the scales developed by Marvel and Lumpkin (2007) and Gatignon et al. (2002); emotional healing was based on the scale by Barbuto and Wheeler (2006), in which this behaviour is one of the characteristics of servant leaders; and organisational learning capability was measured using the items validated by Chiva et al. (2007).

The average variance extracted (Fornell and Larcker, 1981), the Bentler-Bonett coefficient, and the magnitude of the factor loadings were taken as references to evaluate convergent validity.

For discriminant validity to exist, the square root of average variance extracted must be greater than the inter-construct correlations, thereby suggesting that each construct is more strongly related to its own measures than to others (Table IV).

Insert Table II

Insert Table III 


\subsection{Testing the research hypotheses}

The relationship between emotional healing and organisational learning capability was tested as a first step $(\mathrm{a}=0.49, \mathrm{t}=3.71, \mathrm{p}<0.00)$, and supported the first hypothesis of this study. Then, the second hypothesis was evaluated, the results confirming the positive effect of organisational learning capability on radical innovation $(\mathrm{b}=0.30, \mathrm{t}=2.31, \mathrm{p}<0.02)$.

New trends in mediation analysis do not require evidence of a total effect to estimate direct and indirect effects. Nonetheless, the results of the total effect (Figure 1) were statistically different from zero $(\mathrm{c}=0.23, \mathrm{t}=2.50, \mathrm{p}<0.01)$. The next step was to analyse different conditions that must be met to support the mediation. All of them were met, thereby confirming the mediating role of organisational learning capability in the relationship between emotional healing and radical innovation (Figure 3): (1) the significant relationship between emotional healing and radical innovation becomes non-significant when it includes the mediating effect of organisational learning capability $(\mathrm{c} 1=0.11, \mathrm{t}=1.00, \mathrm{p}>0.05)$; (2) the mediated model explains more variance than the direct effect model $(0.13$ vs. 0.05$)$; (3) there is a significant relationship between emotional healing and organisational learning capability $(\mathrm{a}=0.49, \mathrm{t}=$ $3.71, \mathrm{p}<0.00$ ), thus confirming Hypothesis 1 ; and (4) between organisational learning capability and radical innovation $(\mathrm{b}=0.30, \mathrm{t}=2.31, \mathrm{p}<0.02)$, thereby confirming Hypothesis 2 . 
Finally, bootstrapping analyses were conducted to test the significance of the mediated effect (Hayes, 2013; MacKinnon et al., 2012). The estimated indirect effect of emotional healing on radical innovation was 0.15 . The $95 \%$ bias-corrected confidence interval for the indirect effect based on a 5,000 bootstrap sample was entirely above zero (0.05 to 0.30$)$. Consequently, the indirect effect of emotional healing on radical innovation is significantly different from zero, and so the null hypothesis of no mediation can be rejected. Therefore, Hypothesis 3 is confirmed.

None of the control variables had a significant effect on radical innovation ( size: $\mathrm{d} 1=0.07, \mathrm{t}=$ $0.81, \mathrm{p}>0.05$; sector: $\mathrm{d} 2=-0.02, \mathrm{t}=-0.22, \mathrm{p}>0.05$; market share: $\mathrm{d} 3=-0.14, \mathrm{t}=-1.63, \mathrm{p}>0.05)$. 
Insert Figure 2

Insert Figure 3

\section{Discussion}

The goal of the present research was to analyse the mediating effect of organisational learning capability in the relationship between emotional healing and radical innovation. In a turbulent globalised environment in which companies must innovate to be competitive, the present study provides some interesting new findings. Results confirmed all the proposed hypotheses in the conceptual model.

The study's conclusions have theoretical implications for the fields of leadership, innovation and organisational learning capability. Leadership has been highlighted as an important element to promote innovation in organisations. In this vein, recent calls in the leadership literature suggest the need for further study of this relationship, focusing on new leadership styles and behaviours (e.g. Hughes et al., 2018; Yukl, 2012). The present study focused on emotional healing. Although this concept has been highlighted as a relevant leader behaviour, it is only mentioned in literature reviews. To the best of our knowledge, this is the first study to empirically analyse its consequences in an organisational context. Previous studies have suggested that taking into account followers' emotions or managing employees' emotions is an effective mechanism for promoting innovation. For instance, some authors have found or suggested 
positive relationships between emotional capability or emotional intelligence and innovation. However, emotional healing goes beyond these concepts by attending to followers' emotions and playing a proactive role by listening, supporting and providing guidance to those who suffer and have traumatic experiences at work. This is especially important in organisations that want to develop innovations. Innovation is a complicated process that is likely to fail, and this is particularly true when developing radical innovations, which have a high failure rate. Therefore, it is important to promote positive organisational contexts in which employees feel safe and confident to experiment, question things and take risks. Based on the results, emotional healing seems to be a mechanism that organisational leaders can use to empower, engage and motivate workers, thereby creating an atmosphere in which employees feel comfortable to share new ideas and promote completely new products and services.

On the other hand, this study has implications for the organisational learning capability literature. In line with previous studies, our results confirm organisational learning capability as an important mechanism to boost radical innovation. In addition, this construct appears to be the vehicle through which leadership promotes radical innovation. In other words, our results reinforce the idea that organisational learning is one of the paths through which leaders can promote innovation. Leader behaviours related to new leadership styles may create the appropriate organisational context in which employees take risks, experiment or communicate across departments and with the external environment, which in turn can lead to completely new ideas and radical innovations. Employees regard these leaders as trustworthy, which gives them the confidence to try new ideas and take risky decisions, because failure is a part of innovation that will not necessarily have negative consequences. So, despite setbacks and frustration, these employees receive the support from their leaders that they need to learn from failure and persevere with innovative projects. 
There are also implications for the literature on the antecedents of radical innovations. Given that radical innovation has such important outcomes for companies, including better financial results, improved organisational image or higher competitive position, a great deal of research has investigated how organisations can develop these innovations successfully. In recent years, various authors have identified the need for further knowledge on the role of leadership in radical innovation; this study has attempted to shed light in this field by analysing emotional healing from a leadership perspective and its influence on radical innovation. Although concern for others, prosocial behaviours and positive work climates are increasingly important in our competitive environment, little work has been carried out on these types of behaviours in the field of radical innovation. Consequently, this research represents a step forward in the literature on facilitators of radical innovations.

\subsection{Practical implications}

The study also has implications for practitioners. Our results provide some guidelines for companies that are trying to develop radical innovations by improving the workplace conditions. Nowadays, many companies are showing a willingness to create positive organisational contexts in which employees feel motivated, engaged and committed to the organisation. The business philosophy usually extols excellence, quality and perfection as mechanisms to achieve superior results and ideal performance, and ignores emotions, which are considered a weakness. However, the day-to-day reality in organisational contexts shows that problems and failure are commonplace, especially when developing innovations, and that they have a negative impact on the emotional health and morale of workers. It is therefore necessary to consider employees' emotions and take a proactive approach in order to mitigate the negative 
consequences of work-related trauma and setbacks. Emotional healing helps to create a positive work environment and, in such a trusting context, employees are more likely to be creative and develop new ideas that can potentially lead to radical innovations.

Companies can also use human resources practices to detect personal profiles that meet the requirements to develop emotional healing behaviour. When recruiting or promoting new leaders, it would be interesting to evaluate whether candidates inspire trust and are good listeners, and if they have the empathy needed to evaluate other people's problems and a proactive attitude to help their colleagues with their emotional issues. Moreover, leadership skills and competences may be developed through training programs, even when it comes to prosocial behaviours (Domínguez-Escrig et al., 2016). Similarly, other researchers highlighted that healing behaviours and listening skills may be fostered in the organisational context (Beck, 2014; Gutierrez-Wirsching et al., 2015), promoting the conditions to boost emotional healing behaviours among leaders.

On the other hand, companies should be vigilant for early signs of negative emotions, which can cause future problems, hamper innovative projects or hinder organisational activity. As Pearson (2017) noted, organisations should seek out troubled employees, be quick to listen and offer support, and deal with negative emotions such as anger, anxiety or fear, etc.

\subsection{Limitations and future research}

This study presents some limitations that must be taken into consideration. Firstly, the selected sample frame is limited to companies recognised for their excellence in managing human resources. Our 
results therefore only apply to this type of organisation. In addition, the sample frame is heterogeneous in terms of size and sector. Future research should investigate whether there are differences between companies in different sectors, and could also focus on large or SME companies. Although in the present study these constructs were used as control variables and non-significant results were obtained, previous research has suggested that size and sector may influence companies' innovative outcomes. Therefore, comparative studies with a focus on these variables may shed light on how emotional healing facilitates organisational learning and fuels radical innovation.

Continuing with the idea of comparative studies, this research was conducted in Spain and our conclusions are therefore limited to companies in this country. According to the European Innovation Scoreboard (EIS), innovative performance varies significantly across EU countries. The EIS annual report classifies countries according to their innovation performance. Spain is a moderate innovator, so it would be of great interest to compare our results with results for countries that obtain higher scores and are considered strong innovators or innovator leaders.

The present study also focuses on radical innovation and does not analyse the effects of emotional healing and organisational learning capability in other typologies, such as incremental innovation. Future research should take this limitation into account. In addition, no differentiation was made between service and product innovation in the questionnaire, which opens up another line for further research, along with the study of process innovations. Moreover, innovation stages were not differentiated in this study, so analysing how the variables used here influence idea generation, implementation or commercialisation would provide a more accurate picture of the relationship between emotional healing, organisational learning capability and radical innovation outcomes. 
Furthermore, as this study seems to be the first to empirically test the effects of emotional healing from a leadership perspective in the organisational context, more research is still required. Some interesting avenues to extend knowledge about this leadership behaviour would be to explore how this behaviour influences performance, trust, job satisfaction, motivation, engagement or happiness. Moreover, and following recent calls in the literature, more research is needed into concrete leadership behaviours, such as forgiveness or stewardship, and new leadership styles, such as servant or empowering leadership.

Another possible limitation is related to the mediating variable. This study only tests the mediating effect of organisational learning capability. However, other possible mechanisms may explain the positive effect of emotional healing on radical innovation. Continuing with the theme of organisational learning, differentiating between typologies such as generative or adaptive learning may provide more details about what kind of learning is promoted by this leadership behaviour. On the other hand, other mediating variables related to these new trends in leadership, such as altruism or prosocial motivation, could also be considered for further research.

Finally, this study was based on the opinions of company leaders. Although these professional profiles have been considered as a reliable source of information, future research should gather information from organisational leaders and employees in order to conduct multilevel analyses.

Future research should take into account the limitations of this study in order to strengthen the weak points identified here and improve the knowledge related to the variables analysed. 


\section{References}

Akgün, A. E., Keskin, H., Byrne, J. C. and Aren, S. (2007). "Emotional and learning capability and their impact on product innovativeness and firm performance", Technovation, Vol. 27 No. 9, pp. 501513. https://doi.org/10.1016/j.technovation.2007.03.001

Akgün, A. E., Keskin, H. and Byrne, J. (2009). “Organizational emotional capability, product and process innovation, and firm performance: An empirical analysis", Journal of Engineering and Technology Management, Vol. 26 No. 3, pp. 103-130. https://doi.org/10.1016/j.jengtecman.2009.06.008

Anderson, J. C. and Gerbing, D. W. (1988). "Structural equation modeling in practice: A review and recommended two-step approach", Psychological Bulletin, Vol. 103 No. 3, pp. 411-423. https://doi.org/10.1037/0033-2909.103.3.411

Antonacopoulou, E. P. and Gabriel, Y. (2001). "Emotion, learning and organizational change: Towards an integration of psychoanalytic and other perspectives", Journal of Organizational Change Management, Vol. 14 No. 5, pp. 435-451. https://doi.org/10.1108/EUM0000000005874

Ashkanasy, N.M. (2003), "Emotions in organizations: a multi-level perspective", Dansereau, F. and Yammarino, F.J. (Ed.) Multi-Level Issues in Organizational Behavior and Strategy (Research in Multi-Level Issues, Vol. 2), Emerald Group Publishing Limited, Bingley, pp. 9-54. https://doi.org/10.1016/S1475-9144(03)02002-2 
Ashkanasy, N. M., and Ashton-James, C. E. (2007), "Positive emotion in organizations: A multi-level framework". Cooper, C.L. and Nelson D. (Eds.), Positive organizational behavior, John Wiley and Sons, Chichester, UK, pp. 57-73.

Ashkanasy, N. M. and Dorris, A. D. (2017), "Emotions in the workplace", Annual Review of Organizational Psychology and Organizational Behavior, Vol.4, pp.67-90. https://doi.org/10.1146/annurev-orgpsych-032516-113231

Ayalon, O. (1998). "Community healing for children traumatized by war", International Review of Psychiatry, Vol.10 No.3, pp.224-233. https://doi.org/10.1080/09540269874817

Barbuto Jr, J. E. and Wheeler, D. W. (2006). "Scale development and construct clarification of servant leadership", Group \& Organization Management, Vol. 31 No. 3, pp. 300-326. https://doi.org/10.1177/1059601106287091

Basch, J., and Fisher, C. D. (2000), “Affective job events - emotions matrix: A classification of job related events and emotions experienced in the workplace". Ashkanasy, N. Zerbe, W and Hartel C. (Eds.), Emotions in the Workplace: Research, Theory and Practice, Quorum Books, pp. 36-48.

Beck, C. D. (2014). “Antecedents of servant leadership: A mixed methods study”, Journal of Leadership \& Organizational Studies, Vol. 21 No. 3, pp. 299-314. https://doi.org/10.1177/1548051814529993

Chang, S. J., Van Witteloostuijn, A. and Eden, L. (2010). "From the editors: Common method variance in international business research", Journal of International Business Studies, Vol. 41, pp. 178184. https://doi.org/10.1057/jibs.2009.88 
Chiva, R. and Alegre, J. (2008). "Emotional intelligence and job satisfaction: the role of organizational learning capability", Personnel Review, Vol. 37 No. 6, pp. 680-701. https://doi.org/10.1108/00483480810906900

Chiva, R., Alegre, J. and Lapiedra, R. (2007). "Measuring organisational learning capability among the workforce", International Journal of Manpower, Vol. 28 No. 3/4, pp. 224-242. https://doi.org/10.1108/01437720710755227

Domínguez-Escrig, E., Mallén, F. F., Chiva, R. and Lapiedra, R. (2016). "How does altruistic leader behavior foster radical innovation? The mediating effect of organizational learning capability", Leadership \& Organization Development Journal, Vol. 37 No. 8, pp. 1056-1082. https://doi.org/10.1108/LODJ-03-2015-0050

Domínguez-Escrig, E., Mallén, F. F., Lapiedra, R. and Chiva, R. (2019). “The influence of leaders' stewardship behavior on innovation success: the mediating effect of radical innovation", Journal of Business Ethics, Vol. 159 No. 3, pp. 849-862. https://doi.org/10.1007/s10551-018-3833-2

Fornell, C. and Larcker, D. F. (1981). "Evaluating structural equation models with unobservable variables and measurement error", Journal of Marketing Research, pp. 39-50. https://doi.org/10.1177/002224378101800104

Frijda, N.H. (1986), The Emotions, New York: Cambridge Univ. Press

Frost, P.J. (2003), Toxic emotions at work, Boston: Harvard Bus. Sch. Press 
García-Granero, A., Llopis, Ó., Fernández-Mesa, A. and Alegre, J. (2015). “Unraveling the link between managerial risk-taking and innovation: The mediating role of a risk-taking climate", Journal of Business Research, Vol. 68 No. 5, pp. 1094-1104. https://doi.org/10.1016/j.jbusres.2014.10.012

Gatignon, H., Tushman, M. L., Smith, W. and Anderson, P. (2002). “A structural approach to assessing innovation: Construct development of innovation locus, type, and characteristics", Management science, Vol. 48 No. 9, pp. 1103-1122. https://doi.org/10.1287/mnsc.48.9.1103.174

Gutierrez-Wirsching, S., Mayfield, J., Mayfield, M. and Wang, W. (2015), "Motivating language as a mediator between servant leadership and employee outcomes", Management Research Review, Vol. 38 No. 12, pp. 1234-1250. https://doi.org/10.1108/MRR-01-2014-0009

Gupta, V. (2015). "Role of positive emotions in organisational coping", Journal of Organisation \& Human Behaviour, Vol. 4. No. 2, pp. 52-61. https://doi.org/10.21863/johb/2015.4.2and3.014

Hayes, A. F. (2013). Introduction to mediation, moderation, and conditional process analysis: A regression-based approach. Guilford Publications.

Hilton Brown, E. (1997). “Improving organizational health by addressing organizational trauma”, Journal of Organizational Change Management, Vol. $10 \quad$ No. 2, pp. 175-178. https://doi.org/10.1108/09534819710160835 
Hughes, D. J., Lee, A., Tian, A. W., Newman, A. and Legood, A. (2018). "Leadership, creativity, and innovation: A critical review and practical recommendations", The Leadership Quarterly, Vol. 29 No. 5, pp. 549-569. https://doi.org/10.1016/j.leaqua.2018.03.001

Huy, Q. N. (1999). "Emotional capability, emotional intelligence, and radical change”, Academy of Management Review, Vol. 24 No. 2, pp. 325-345. https://doi.org/10.5465/amr.1999.1893939

Jackson, S. W. (1992). "The listening healer in the history of psychological healing”, American Journal of psychiatry, Vol.149, pp.1623-1623.

Ikävalko, H., Hökkä, P., Paloniemi, S. and Vähäsantanen, K. (2020). "Emotional competence at work”, Journal of Organizational Change Management, Vol.33 No.7, pp. 1485-1498. https://doi.org/10.1108/JOCM-01-2020-0024

Jit, R., Sharma, C. S. and Kawatra, M. (2017). "Healing a broken spirit: Role of servant leadership", Vikalpa: The Journal for Decision Makers, Vol. 42 No. 2, pp. 80-94. https://doi.org/10.1177/0256090917703754

Kohrt, B. A., Ottman, K., Panter-Brick, C. Konner, M., and Patel, V. (2020). "Why we heal: The evolution of psychological healing and implications for global mental health". Clinical Psychology Review, Vol.82, pp.101920. https://doi.org/10.1016/j.cpr.2020.101920.

Koberg, C. S., Detienne, D. R. and Heppard, K. A. (2003). “An empirical test of environmental, organizational, and process factors affecting incremental and radical innovation". The Journal of 
High Technology Management Research, Vol. 14 No. 1, pp. 21-45.

https://doi.org/10.1016/S1047-8310(03)00003-8

Liden, R. C., Wayne, S. J., Zhao, H. and Henderson, D. (2008). "Servant leadership: Development of a multidimensional measure and multi-level assessment”, The Leadership Quarterly, Vol. 19 No. 2, pp. 161-177. https://doi.org/10.1016/j.leaqua.2008.01.006

Liden, R. C., Wayne, S. J., Liao, C. and Meuser, J. D. (2014). “Servant leadership and serving culture: Influence on individual and unit performance”, Academy of Management Journal, Vol. 57 No. 5, pp. 1434-1452. https://doi.org/10.5465/amj.2013.0034

MacKinnon, D. P., Coxe, S. and Baraldi, A. N. (2012). "Guidelines for the investigation of mediating variables in business research", Journal of Business and Psychology, Vol. 27 No. 1, pp. 1-14. https://doi.org/10.1007/s10869-011-9248-z

Marvel, M. R. and Lumpkin, G. T. (2007). “Technology entrepreneurs' human capital and its effects on innovation radicalness", Entrepreneurship Theory and Practice, Vol. 31 No. 6, pp. 807-828. https://doi.org/10.1111/j.1540-6520.2007.00209.x

Nunnally, J. C. (1978), Psychometric Theory, New York: McGraw-Hill

Pearson, C. M. (2017). "The smart way to respond to negative emotions at work", MIT Sloan Management Review, Vol. 58 No. 3, p. 49. 
Porter, L. W. and McLaughlin, G. B. (2006). "Leadership and the organizational context: like the weather?", The Leadership Quarterly, Vol. 17 No. 6, pp. 559-576. https://doi.org/10.1016/j.leaqua.2006.10.002

Powley, E.H. and Cameron, K.S, (2006). "Organizational Healing: Lived Virtuousness Amidst Organizational Crisis”, Journal of Management, Spirituality \& Religion, Vol.3 No.1-2, pp.13-33. https://doi.org/10.1080/14766080609518609

Powley, E. H. and Piderit, S. K. (2008). "Tending wounds: Elements of the organizational healing process", The Journal of Applied Behavioral Science, Vol.44 No.1, pp.134-149. https://doi.org/10.1177/0021886308314842

Powley, E. H. (2013). “The process and mechanisms of organizational healing”, The Journal of Applied Behavioral Science, Vol. 49 No. 1, pp. 42-68. https://doi.org/10.1177/0021886312471192

Shipton, H. and Sillince, J. (2013). “Organizational learning and emotion: constructing collective meaning in support of strategic themes", Management Learning, Vol. 44 No. 5, pp. 493-510. https://doi.org/10.1177/1350507612450547

Simpson, B. and Marshall, N. (2010). "The mutuality of emotions and learning in organizations", Journal of Management Inquiry, Vol. 19 No. 4, pp. 351-365. https://doi.org/10.1177/1056492610376531 
Slater, S. F., Mohr, J. J. and Sengupta, S. (2014). "Radical product innovation capability: Literature review, synthesis, and illustrative research propositions", Journal of Product Innovation Management, Vol. 31 No. 3, pp. 552-566. https://doi.org/10.1111/jpim.12113

Spears, L. C. (2002). "Introduction: Tracing the past, present and future of servant-Leadership", Spears, L. C. (Ed.), Focus on leadership, John Wiley, New York, pp. 1-18.

Tippins, M. J. and Sohi, R. S. (2003). "IT competency and firm performance: is organizational learning a missing link?", Strategic Management Journal, Vol. 24 No. 8, pp. 745-761. https://doi.org/10.1002/smj.337

Välikangas, L., Hoegl, M. and Gibbert, M. (2009). "Why learning from failure isn’t easy (and what to do about it): Innovation trauma at Sun Microsystems”, European Management Journal, Vol. 27 No. 4, pp. 225-233. https://doi.org/10.1016/j.emj.2008.12.001

Yukl, G. (2012). "Effective leadership behavior: What we know and what questions need more attention”, Academy of Management Perspectives, Vol. 26 No. 4, pp. 66-85. https://doi.org/10.5465/amp.2012.0088 
Table I. Questionnaire items

Emotional healing (Barbuto and Wheeler, 2006)

EH1. The leaders of this organisation are the ones I would turn to if I had a personal trauma

EH2. The leaders of this organisation are good at helping me with my emotional issues

EH3. The leaders of this organisation are talented at helping me to heal emotionally

EH4. The leaders of this organisation could help me mend my hard feelings

Organisational learning capability (Chiva et al., 2007)

Experimentation

EXP1. People here receive support and encouragement when presenting new ideas.

EXP2. Initiative often receives a favourable response here, so people feel encouraged to generate new ideas.

Risk taking

RISK1. People are encouraged to take risks in this organization.

RISK2. People here often venture into unknown territory.

Interaction with the external environment

ENV1. It is part of the work of all staff to collect, bring back, and report information about what is going on outside the company

ENV2. There are systems and procedures for receiving, collating and sharing information from outside the company.

ENV3. People are encouraged to interact with the environment.

Dialogue

DIA1. Employees are encouraged to communicate.

DIA2. There is a free and open communication within my work group.

DIA3. Managers facilitate communication.

DIA4. Cross-functional teamwork is a common practice here.

Participative decision-making

DEC1- Managers in this organization frequently involve employees in important decisions. 
DEC2. Policies are significantly influenced by the employees' views.

DEC3. People feel involved in main company decisions.

Radical innovation Marvel and Lumpkin (2007), and Gatignon et al. (2002)

RI1. These innovations represent an entirely new type of product/service.

RI2. These innovations can be described as totally new innovations.

RI3. These innovations meet a want or a need that has not been addressed by other products/services.

RI4. These innovations involve a revolutionary change from the latest generation of these products.

RI5. These innovations could be described as a new product line.

RI6. These innovations are significant or leading innovations

Table II. Factor correlations, means and standard deviations

\begin{tabular}{lccccccccc}
\hline & Mean & s.d. & $E H$ & $R I$ & Exp & Risk & Env & Dia & Dec \\
\hline EH & 3.61 & 0.58 & 1 & & & & & & \\
RI & 5.43 & 0.99 & $0.20^{*}$ & 1 & & & & & \\
Exp & 4.02 & 0.56 & $0.27^{* *}$ & 0.13 & 1 & & & & \\
Risk & 3.37 & 0.80 & 0.04 & 0.07 & $0.20^{*}$ & 1 & & & \\
Env & 3.67 & 0.68 & $0.22^{* *}$ & 0.07 & 0.09 & $0.24^{* *}$ & 1 & & \\
Dia & 4.11 & 0.53 & $0.36^{* *}$ & $0.19^{*}$ & $0.34^{* *}$ & $0.20^{*}$ & $0.34^{* *}$ & 1 & \\
Dec & 3.51 & 0.69 & $0.28^{* *}$ & $0.17^{*}$ & $0.27^{* *}$ & $0.20^{*}$ & $0.32^{* *}$ & $0.51^{* *}$ & 1 \\
\hline
\end{tabular}

Notes: For the standard deviations and factor correlations, we used the mean of the items making up each dimension.

* Significant correlation $(p<0.05)$. ** Significant correlation at $p<0.01$.

Note: $E H=$ Emotional healing; $R I=$ Radical innovation; $E X P=$ Experimentation; $R I S K=$ Acceptance of risk; $E N V=$ Interaction with the external environment $; D I A=$ Dialogue; $D E C=$ Participative decision-making . 
Table III. Reliability of the measurement scales

\begin{tabular}{lccc}
\hline Construct & $\begin{array}{c}\text { Composite } \\
\text { reliability }\end{array}$ & $\begin{array}{c}\text { Average } \\
\text { variance } \\
\text { extracted }\end{array}$ & $\begin{array}{c}\text { Cronbach's } \\
\text { alpha }\end{array}$ \\
\hline Emotional healing (4 items) & 0.88 & 0.64 & 0.87 \\
Radical innovation (6 items) & 0.89 & 0.58 & 0.88 \\
Experimentation (2 items) & 0.82 & 0.70 & 0.79 \\
Acceptance of risk (2 items) & 0.83 & 0.72 & 0.79 \\
$\begin{array}{l}\text { Interaction with the external environment } \\
\text { (3 items) }\end{array}$ & 0.82 & 0.61 & 0.81 \\
Dialogue (4 items) & 0.85 & 0.59 & 0.85 \\
Participative decision-making (3 items) & 0.89 & 0.74 & 0.89 \\
\hline
\end{tabular}

Table IV. Discriminant validity

\begin{tabular}{lrrrrrrr}
\hline & $E H$ & $R I$ & Exp & Risk & Env & Dia & Dec \\
\hline EH & $(0.80)$ & & & & & & \\
$R I$ & $0.20^{*}$ & $(0.76)$ & & & & & \\
Exp & $0.27^{* *}$ & 0.13 & $(0.84)$ & & & & \\
Risk & 0.04 & 0.07 & $0.20^{*}$ & $(0.85)$ & & & \\
Env & $0.22^{* *}$ & 0.07 & 0.09 & $0.24^{* *}$ & $(0.78)$ & & \\
Dia & $0.36^{* *}$ & $0.19^{*}$ & $0.34^{* *}$ & $0.20^{*}$ & $0.34^{* *}$ & $(0.77)$ & \\
Dec & $0.28^{* *}$ & $0.17^{*}$ & $0.27^{* *}$ & $0.20^{*}$ & $0.32^{* *}$ & $0.51^{* *}$ & $(0.86)$ \\
\hline
\end{tabular}

Notes: On the diagonal, data correspond to AVE square root (in brackets). Below the diagonal, data show the correlations between constructs.

** Significant correlation at $p<0.01$. * Significant correlation at $p<0.05$.

$E H=$ Emotional healing; $R I=$ Radical innovation; $E X P=$ Experimentation; $R I S K=$ Acceptance of risk; $E N V=$ Interaction with the external environment $; D I A=$ Dialogue; $D E C=$ Participative decision-making . 
Figure 1. Conceptual model and hypotheses

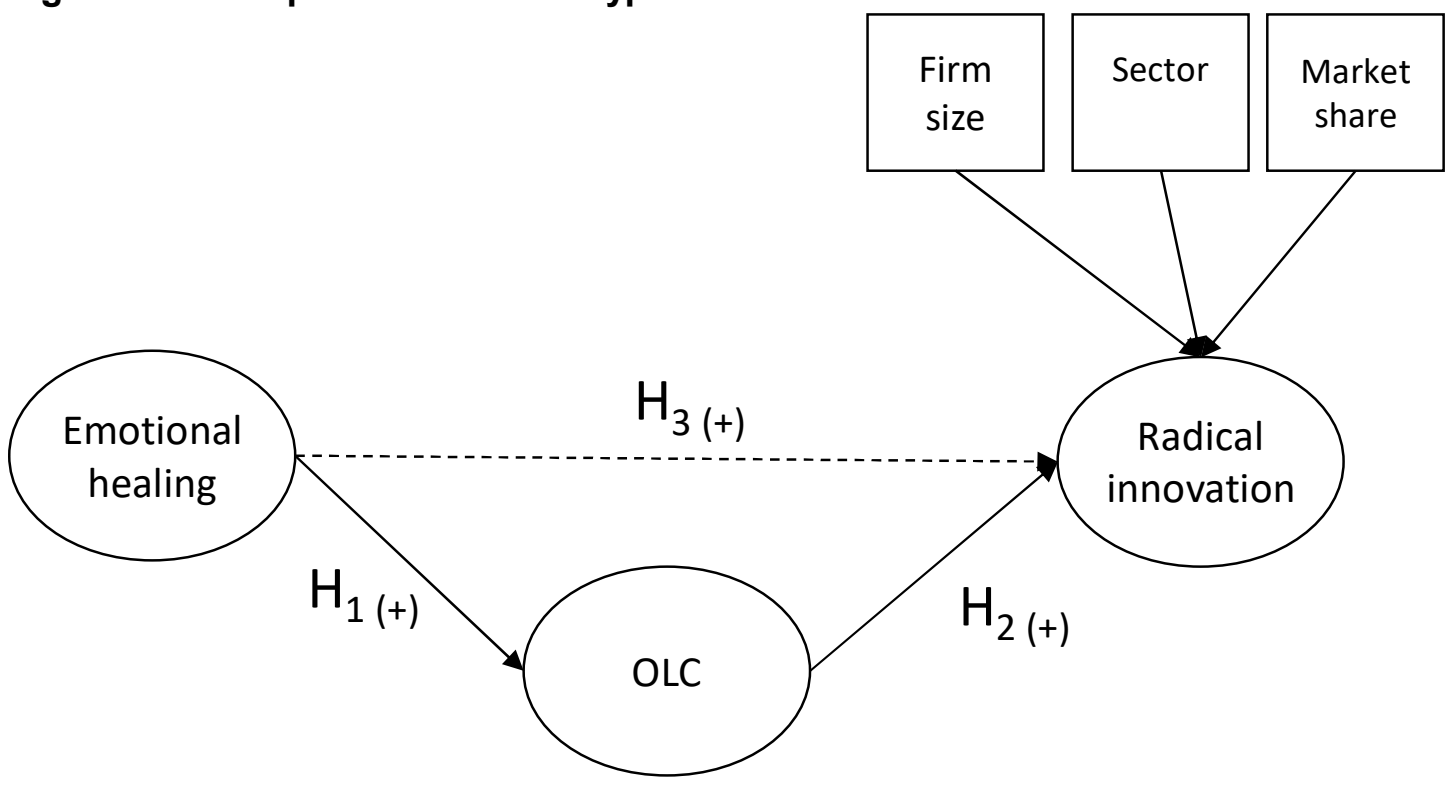

Figure 2. Total effect model

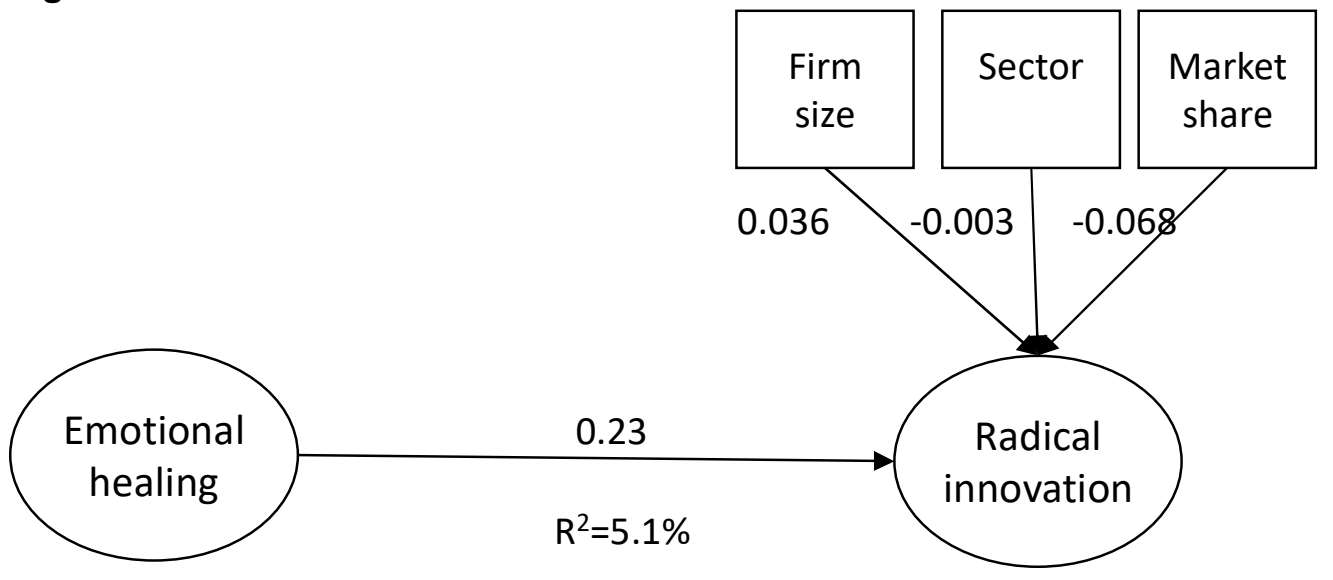

$\begin{array}{lc}\text { S-B chi-square } & 87.313 \\ \text { g.l. } & 58 \\ \text { P-value } & 0.008 \\ \text { S-B chi-square/d.f. } & 1.505 \\ \text { BBNFI } & 0.902 \\ \text { BBNNFI } & 0.951 \\ \text { CFI } & 0.964 \\ \text { RMSEA } & 0.059\end{array}$


Figure 3. Mediation model

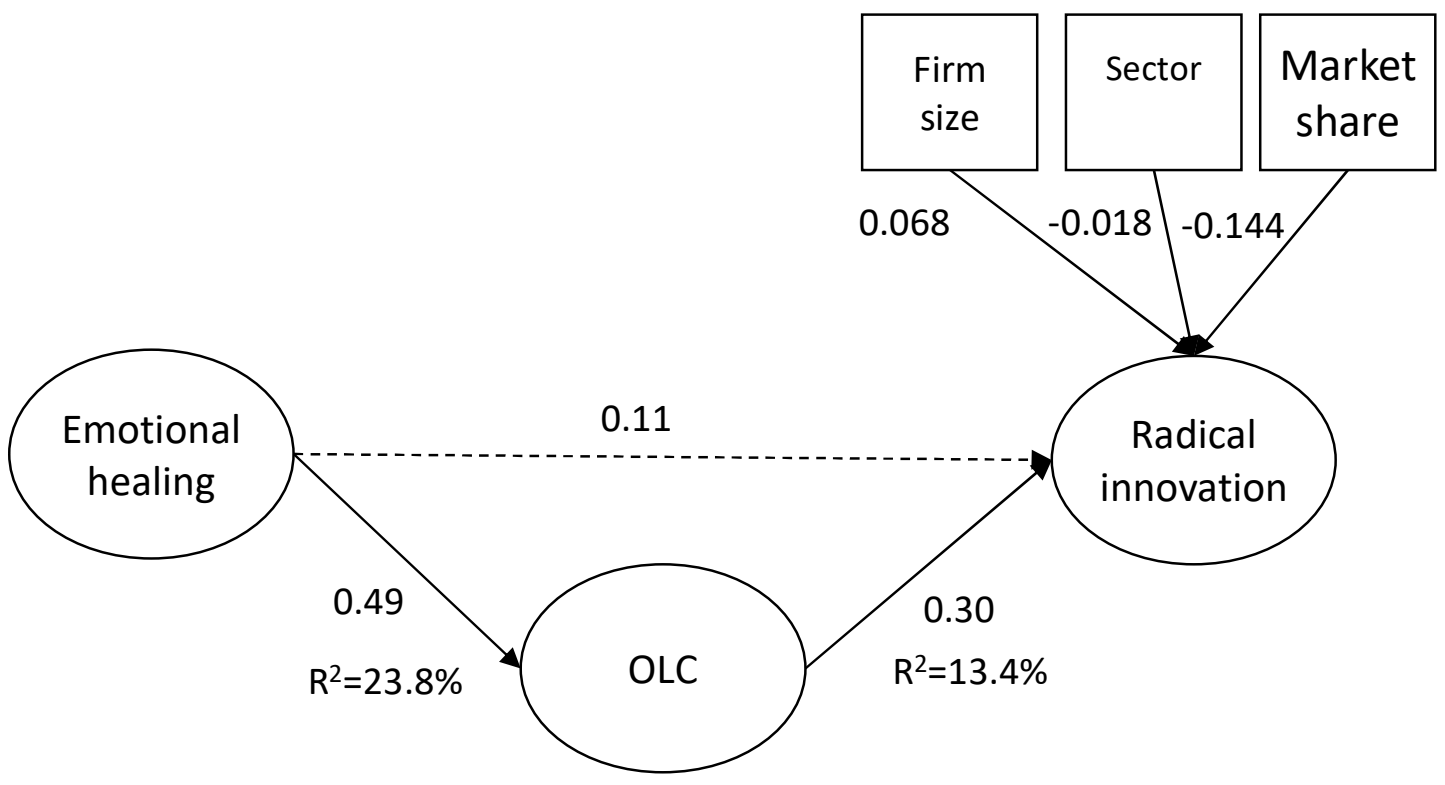

\begin{tabular}{|lc|}
\hline S-B chi-square & 404.877 \\
g.l. & 310 \\
P-value & 0.000 \\
S-B chi-square/d.f. & 1.306 \\
BBNFI & 0.814 \\
BBNNFI & 0.949 \\
CFI & 0.941 \\
RMSEA & 0.046 \\
\hline
\end{tabular}

